\title{
Investigation of Wave Farm Electrical Network Configurations
}

\author{
Mr. Fergus Sharkey ${ }^{1, *}$, Dr. Michael Conlon ${ }^{2}$, Mr. Kevin Gaughan ${ }^{2}$ \\ ${ }^{1}$ Dublin Institute of Technology, Dublin, Ireland; ESB International, Dublin, Ireland \\ ${ }^{2}$ Dublin Institute of Technology, Dublin, Ireland \\ * Corresponding author: Tel: +353 1 7038000,E-mail: fergus.sharkey@esbi.ie
}

\begin{abstract}
Wave Energy Converters (WECs) have been in development for a number of decades and some devices are now close to becoming a commercial reality. As such, pilot projects are being developed, particularly in the UK and Ireland, to deploy WECs on a pre-commercial array scale. There is little experience in the wave energy or utility industry of designing and installing electrical networks for WEC arrays with the closest comparison being offshore wind farms. There are some key features of WECs which will ultimately dictate that the electrical configuration differs from that of offshore wind farms.
\end{abstract}

This paper investigates the potential representative electrical network configurations for small (10MW), medium (40MW) and large scale (150MW) 'wave farms' in order to establish a development path for such projects. The configurations are evaluated for efficiency (power loss), redundancy and short circuit levels. Key interfaces in the electrical infrastructure are identified and discussed. This paper also identifies the key differences between offshore wind farm electrical networks.

Keywords: Wave Energy, Electrical Network, Array

\section{Introduction}

Many countries have ambitious targets by 2020-2030 for ocean energy [1], [2] and there are several ocean energy test facilities with grid connection such as EMEC and Wavehub. Collaborative projects have also explored the area of WEC electrical arrays such as the Equimar Project [3] and these have also been investigated in [4]-[10]. The ultimate ambition is to have large wave farms installed in a similar fashion to offshore wind.

Offshore wind energy projects have been developed up to 300MW installed capacity and it is acknowledged that the industry can serve as a useful source of knowledge for the wave energy sector. Investigating the state of the art in offshore wind farms and also looking at all the information available within the wave energy sector will enable a feasible assessment of wave farms to be studied.

\section{Offshore Wind Electrical Systems}

A survey of the 25 largest offshore wind farms (as of December 2010) shows that the majority are installed less than $15 \mathrm{~km}$ from shore and in less than $30 \mathrm{~m}$ depth. As the installed capacity and distance from shore increased offshore, platform based, substations were required in order to step up the voltage to HVAC $(>100 \mathrm{kV})$ for transmission to shore. The requirement for an offshore substation is typically above $100 \mathrm{MW}$ capacity or $10 \mathrm{~km}$ distance from shore.

HVDC transmission will be used in larger offshore wind farms located far from shore such as the BARD Offshore Wind Farm (400MW, 100km from shore) which is expected to be commissioned by 2011. There are also development projects on deepwater wind farms and floating wind turbines [11].

All offshore wind farms have a MVAC infield network, typically 20-36kV, with the majority $>30 \mathrm{kV}$. The infield network configuration of offshore wind farms is typically a series of radial circuits containing 7-8 turbines connected back to a central location (either onshore or offshore), as illustrated in Fig. 1. The radial circuit is protected using switchgear in the wind 
turbines and the substation. The cables in each radial are tapered in size towards the radial extents and this is viewed as the best way to minimise cable costs [12]

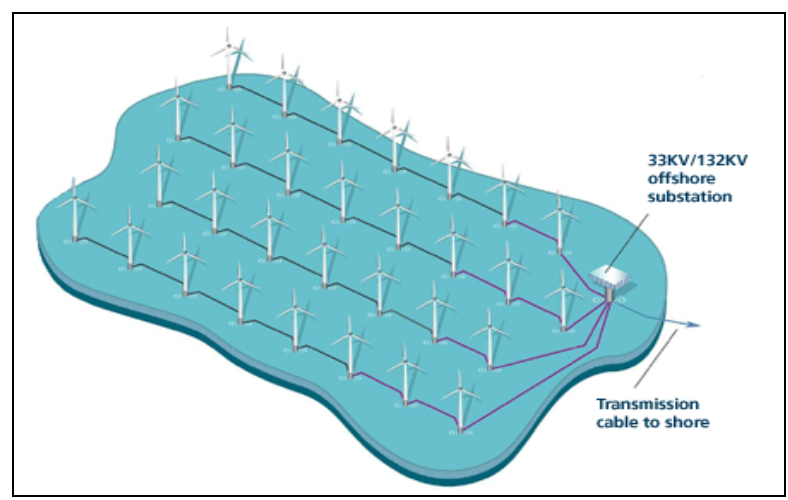

Fig. 1 Typical electrical layout of offshore wind farm [Source: Barrow Wind Farm]

Redundancy and Sectionalising have been proposed in [13] \& [14] and have been shown to offer advantages in increasing availability. To date, however, these are rarely utilised due to the inherent additional up front costs.

The average capital expenditure (Capex) for offshore wind in 2009 was $€ 2.3 \mathrm{~m} / \mathrm{MW}$ [15]. From [15] we can also see that for Horns Rev and Nysted offshore wind farms the infield and transmission systems represent $\sim 21 \%$ of the total Capex. The electrical system is a significant proportion of the overall investment in a wind farm and, assuming that capacity factors and costs per MW for WECs approach those achieved by offshore wind, then it is expected that the same will hold true for wave energy.

\section{Wave Energy Device and Site}

The Wave Energy Converter (WEC) used in this study is the Wavebob device [16], which is a point absorber type WEC. The site used for this study is Belmullet, located off the west coast of Ireland, where a test site is currently under development. Using the Wavebob frequency domain model with an electrical rating of $1 \mathrm{MW}$, and a scatter diagram from the test site, the energy yield distribution histogram can be established for a Wavebob device on the site. Fig. 2 shows the energy yield distribution on the site over the course of a year. This demonstrates that almost $20 \%$ of energy yield is from $>90 \%$ output of the device. This information is used in establishing the energy yield efficiency of the electrical network in later sections.

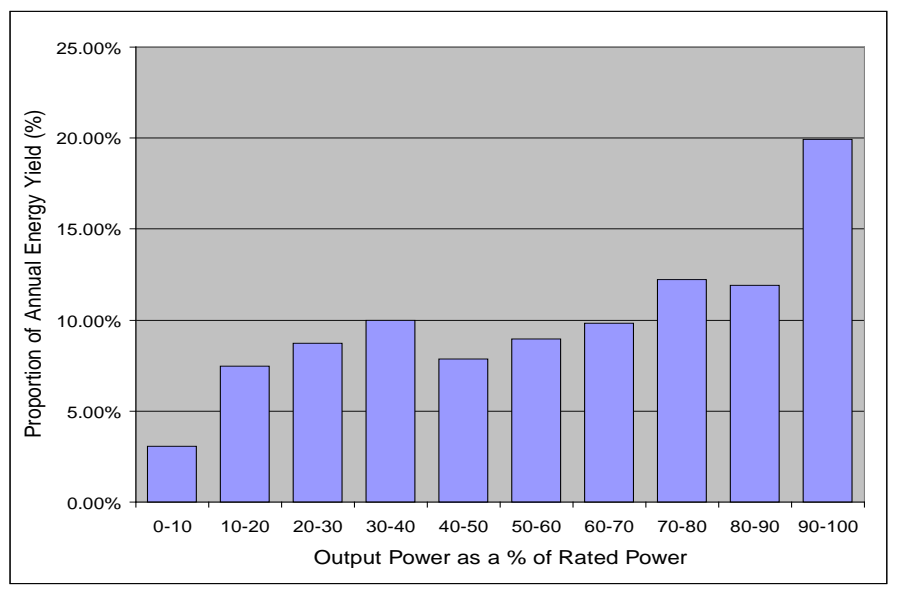

Fig. 2 Energy yield distribution histogram of the Wavebob device at Belmullet 
The Wavebob device is designed for $100 \mathrm{~m}+$ water depth and is typical of floating WECs. Fitzgerald indicates in [17] that such compliantly moored wave energy converters are likely to be moored close to $100 \mathrm{~m}$ in general for survivability reasons. The $100 \mathrm{~m}$ depth contour off the west coast of Ireland lies between 10 and 25km from the shoreline therefore the transmission distance will be selected within this range.

Ultimately the device spacing will be selected based on a variety of factors, namely resource capture and interference [18], [19] mooring footprint [17], marine operation requirements, and minimising cable costs and losses. Therefore 200, 300 and 400 metres device spacings have been selected for this paper. No hydrodynamic interference or directional effects are considered in this paper, however it must be noted that this will limit the maximum rows permissible in an array.

As with offshore wind there will be three types of connection concepts, namely single MV transmission, multiple MV transmission and HV transmission from an offshore substation. As such three candidate wave farms are outlined in Table 1 which will be analysed in this paper.

Table 1 Wave Farms under analysis in this paper.

\begin{tabular}{|ccccc|}
\hline Wave Farm & Capacity & Distance to Shore & Transmission Voltage & \# Transmission Lines \\
\hline 1 & $10 \mathrm{MW}$ & $12 \mathrm{~km}$ & MVAC & 1 \\
\hline 2 & $40 \mathrm{MW}$ & $15 \mathrm{~km}$ & MVAC & $2+$ \\
\hline 3 & $150 \mathrm{MW}$ & $20 \mathrm{~km}$ & HVAC & 1 \\
\hline
\end{tabular}

\section{Methodology}

The wave farm electrical network will be arranged in radial circuits as this has proven the most cost effective option for offshore wind. For larger arrays a 'forked' radial is utilised as this further reduces cable cross sectional area (CSA) in the radials. The effect of additional redundancy is discussed later. All cables will be three-core XLPE with copper conductors. The methodology is as follows;

- Cables (infield and transmission) are sized for maximum continuous current at $10 \mathrm{kV}$, $20 \mathrm{kV} \& 33 \mathrm{kV}$ and, for Wave Farm 3, 132kV. Practical limitations are observed.

- Active Power losses (using lumped parameters) are assessed for the range of $0-100 \%$ wave farm output for each case.

- Using the site/device information given in Section 3 the energy yield efficiency for the wave farm is obtained, i.e. the percentage electrical energy delivered in a year.

- If an energy yield efficiency of $96 \%$ is not achieved initially then an iterative approach is taken to increase the cable CSA to achieve this target.

For practical limitations a minimum cable CSA of $35 \mathrm{~mm}^{2}$ for $10 \mathrm{kV} \& 20 \mathrm{kV}$ and $50 \mathrm{~mm}^{2}$ for $33 \mathrm{kV}$ are assumed. A maximum cable CSA of $500 \mathrm{~mm}^{2}$ is assumed as this is one of the largest dynamic cables installed to date in the Maari Oil Field. 10-15 WECs will be connected in each radial depending on the voltage and the total installed capacity. ABB present the practical limitations for transmission at various voltages in [20] which are replicated below in Table 2. These do not account for maximum distances which are of importance when considering very long lines (i.e. $>50 \mathrm{~km}$ ) which we are not considering here.

Table 2 - Recommended maximum transmission capacities given in [20]

\begin{tabular}{|llllll|}
\hline Voltage & $10 \mathrm{kV}$ & $20 \mathrm{kV}$ & $30 \mathrm{kV}$ & $66 \mathrm{kV}$ & $132 \mathrm{kV}$ \\
\hline $\begin{array}{l}\text { Maximum } \\
\text { Power }\end{array}$ & $15 \mathrm{MW}$ & $30 \mathrm{MW}$ & $50 \mathrm{MW}$ & $100 \mathrm{MW}$ & $200 \mathrm{MW}$ \\
\hline
\end{tabular}


For initial wave farms the voltage rating may initially be limited by certain components, notably cable connectors and submarine power equipment. Given sufficient demand it is likely that these components would become available at higher voltages.

Cable parameters for the study are obtained from [21], Nexans and ABB. No sheath or armour losses are considered, however dielectric losses are calculated in all cases. Infield voltage regulation and switching transients are also not considered, but are naturally important considerations for future work.

For larger arrays the short circuit contribution of the grid and generators must be calculated as the short circuit requirements for the cables may result in a larger CSA cable than dictated by the current carrying requirements. Generator selection is critical here as certain generator types will contribute less fault current than others. In [22] fault currents for synchronous and asynchronous generators are given as 15 p.u. and 8 p.u. respectively, whereas double-fed induction generators and power converter interfaced generators contribute approx 1-2 p.u.

\section{Results}

The layouts of the proposed wave farms illustrated in Fig. 3 are based on a radial approach and within the limitations outlined in Section 4. These are electrical circuit layouts and the physical layout could differ without affecting the cable lengths. These will be analysed according to optimum voltage levels, efficiency and redundancy. The methodology shown in Section 4 will be used to size the cables to achieve 96\% energy yield efficiency, i.e. the annual efficiency of exporting MWhrs.

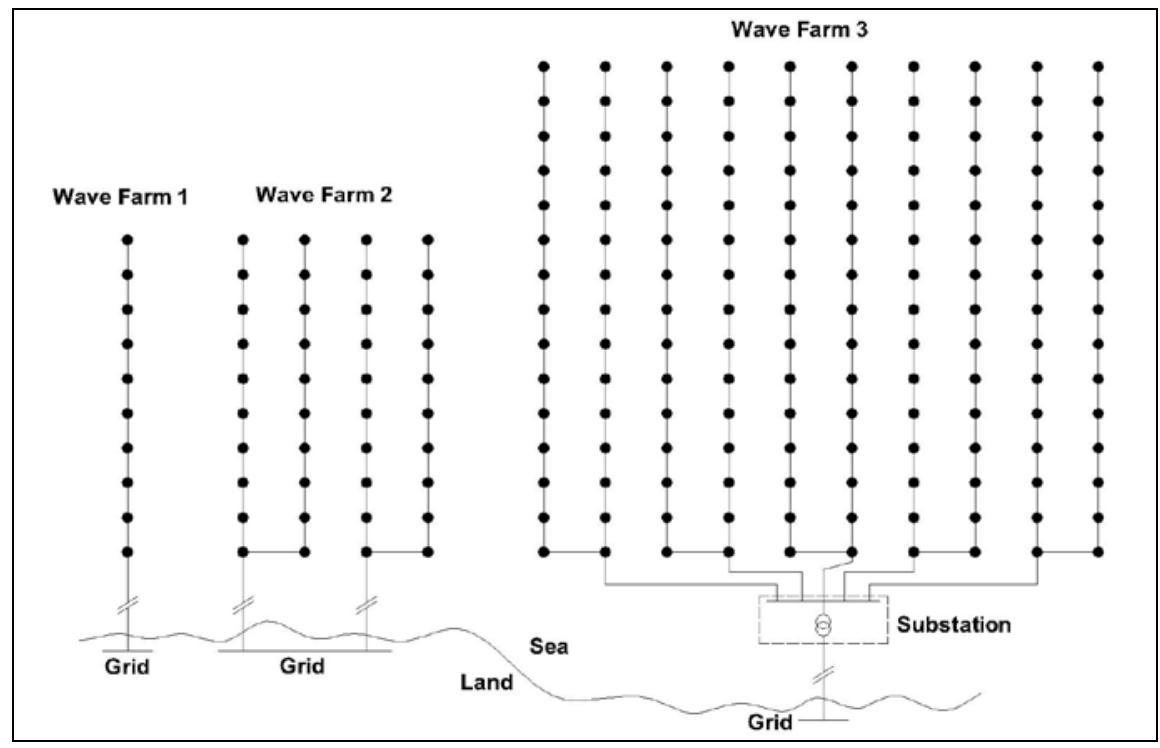

Fig. 3 Selected Wave Farms for Investigation

As mentioned previously this is an iterative process; initially sizing based on maximum continuous current, and then refining based on efficiency. The resultant achievable energy yield efficiencies are illustrated in Fig. 4. $>96 \%$ energy yield efficiency is achievable in almost all cases, however up to almost $99 \%$ is possible for larger wave farms with HVAC connection to shore. Table 3 outlines the cable CSAs required to achieve these figures.

The device spacing has a negligible effect on energy yield efficiency; particularly for larger arrays. Increased spacing will, however, also increase infield cable lengths. The effect of this becomes more pronounced for larger arrays as shown in Fig. 5. Up to 38\% increase in cable length is required for larger wave farms when the spacing is doubled. 


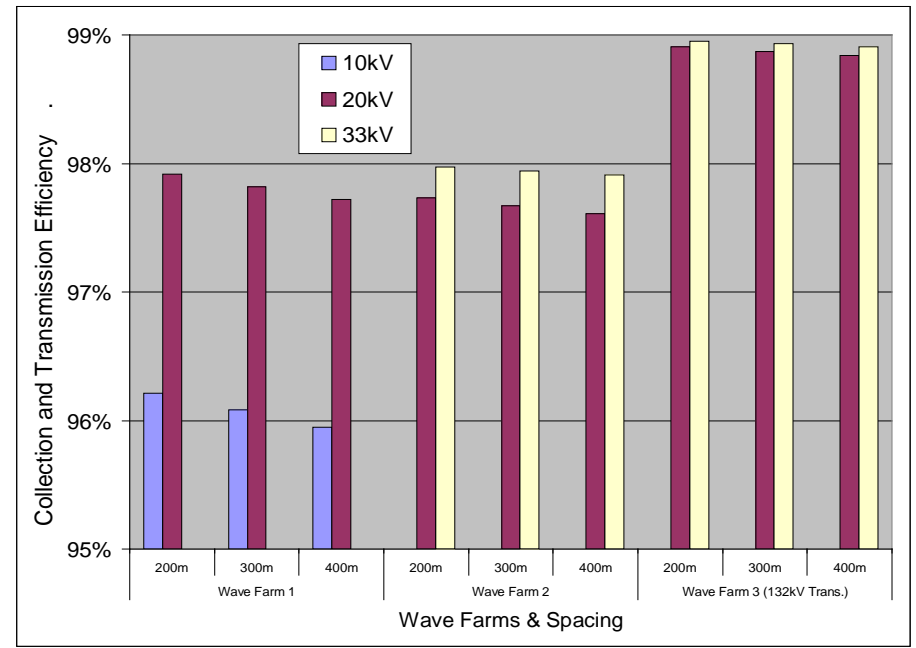

Fig. 4 Achievable Energy Yield Efficiency for Case Study Wave Farms

Table 3 Cable CSA $\left(\mathrm{mm}^{2}\right)$ required to achieve efficiencies shown in Fig. 4.

\begin{tabular}{|lllllll|}
\hline & \multicolumn{2}{l}{ Wavefarm $1(10 \mathrm{MW})$} & \multicolumn{2}{l|}{ Wavefarm 2 (40MW) } & \multicolumn{2}{l|}{ Wavefarm 3 (150MW) } \\
\hline & Infield & Transmission & Infield & Transmission & Infield & Transmission \\
\hline $10 \mathrm{kV}$ & $35-300$ & 400 & N/A & N/A & N/A & N/A \\
\hline $20 \mathrm{kV}$ & $35-95$ & 185 & $35-95$ & 400 & $35-500$ & $500^{*}$ \\
\hline $33 \mathrm{kV}$ & N/A & N/A & $50^{*}$ & 150 & $50-300$ & $500^{*}$ \\
\hline
\end{tabular}

* Minimum or Maximum limits apply

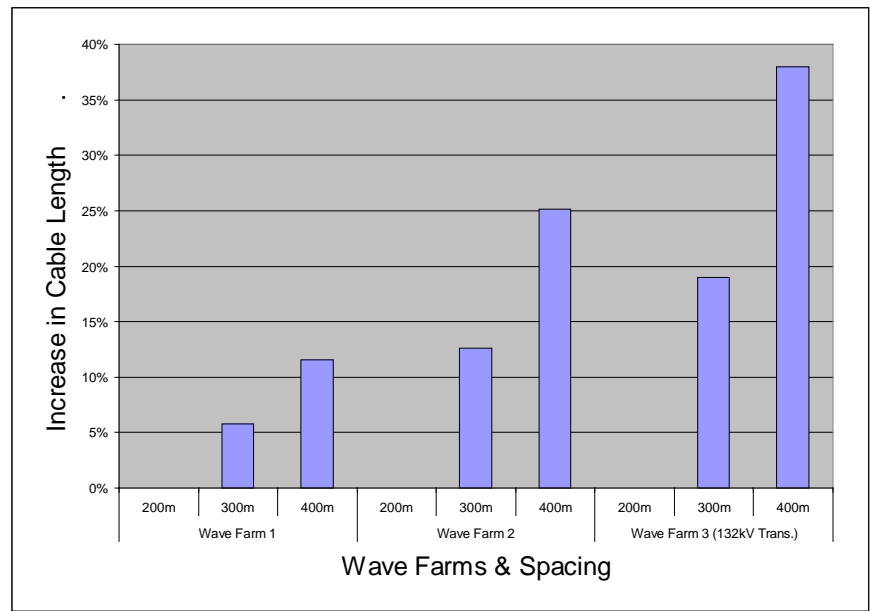

Fig. 5 Percentage Increase in overall farm cable length for spacing increase from $200 \mathrm{~m}$.

Redundancy can be added to the network in a variety of ways and has been proven to increase availability while naturally increase cost. Nevertheless, redundancy could have a dual purpose for wave farms as the WEC devices will have to be routinely removed and brought to port facilities for maintenance. Redundant circuits could provide an alternative route for the power during this maintenance period. Fig. 6 shows some possible redundant circuits for Wave Farm 2, which would involve either increasing CSA of cables within the radial or addition of secondary cables running the length of the radial.

Alternatives to redundancy that could be utilised for wave farm maintenance regimes are;

- The availability of 'standby' or 'dummy' WECs to 'slot' into place.

- A system for temporarily 'bridging' the gap left by the WEC in the electrical circuit.

- Submarine switchgear allowing continued operation of the infield circuit.

These could prove a more cost effective alternative than additional redundancy. 


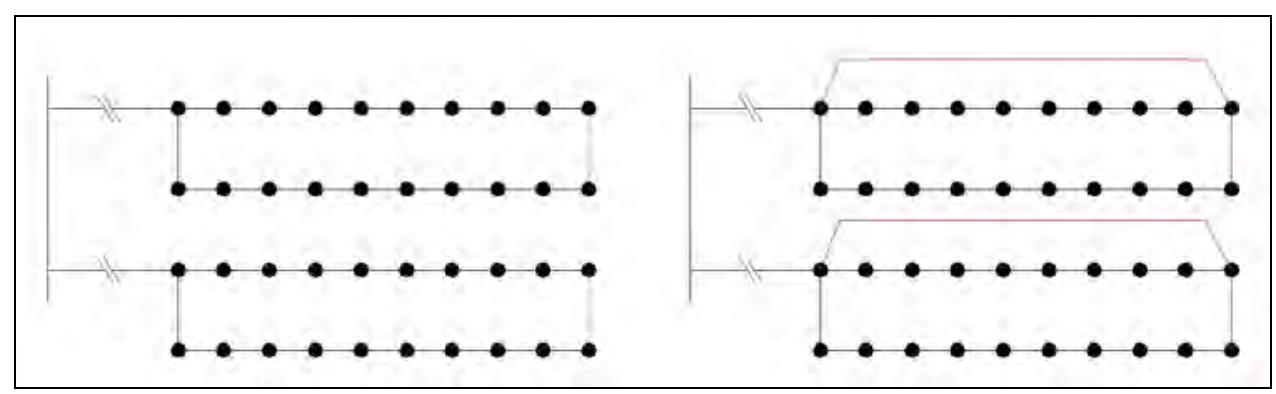

Fig. 6 Wave Farm 2 redundant circuit options

\section{Key Interfaces}

The studied wavefarms are presented in single line diagrams only. There are a number of key interfaces identified which are a functional part of the wave farm. The key interfaces are;

1. Dynamic Cable to WEC interface

2. Dynamic Cable to Static Cable interface

3. MV Switchgear interface (onboard WEC or seabed installation)

4. Offshore Substation (when applicable)

Interfaces 1, $2 \& 3$ are of particular interest as they can provide critical functionality in the wave farm system. Some of this functionality overlaps as outlined in Table 4 below. As each of these three key interfaces overlap, each WEC developer must establish the exact functionality and components required for each of these interfaces

Table 4 Possible functionality of key interfaces

\begin{tabular}{|lllllll|}
\hline \multicolumn{7}{c|}{ Functionality of Key Interfaces } \\
\hline & $\begin{array}{l}\text { Connection/Disco } \\
\text { nnection of WEC }\end{array}$ & Isolation & Protection & $\begin{array}{l}\text { Cable } \\
\text { Installation }\end{array}$ & $\begin{array}{l}\text { Deck/Hull } \\
\text { Penetration }\end{array}$ & $\begin{array}{l}\text { Maintain } \\
\text { Radial Circuit }\end{array}$ \\
\hline 1 & $\mathrm{Y}$ & $\mathrm{Y}^{* *}$ & $\mathrm{~N}$ & $\mathrm{Y}$ & $\mathrm{Y}$ & $\mathrm{N}$ \\
\hline 2 & $\mathrm{Y}$ & $\mathrm{Y}^{* *}$ & $\mathrm{~N}$ & $\mathrm{Y}$ & $\mathrm{Y}$ & $\mathrm{N}$ \\
\hline 3 & $\mathrm{Y}$ & $\mathrm{Y}$ & $\mathrm{Y}$ & $\mathrm{N}$ & $\mathrm{N}$ & $\mathrm{Y}$ \\
\hline
\end{tabular}

$\left({ }^{*}\right.$ with integrated connectors for submarine switchgear; $* *$ with strict control procedures)

Interface 3 (WEC MV switchgear) is significant to the electrical network as it is a necessary protection function but can also be used for redundancy. Most importantly is its function as part of a safety and isolation system. Submarine switchgear systems have been developed mostly for use in the oil and gas industry.

From [23]; for systems above LV in wind farms (on and offshore), the UK HV safety rules apply [24]. [24] states that in order to work on or near HV power systems the equipment should be isolated and earthed with isolation points and earth points locked where practicable. It would be impractical to expect that submarine switchgear, where required for isolation and earthing, could be locked in this position. The safe control of work would be extremely difficult to undertake given submarine switchgear units.

For interface 4, as is the case in offshore wind, an offshore substation would typically be required for wave farms larger than 100MW. As the wave farm in question will be located in $100 \mathrm{~m}$ water depth, although the onboard equipment will be identical, the type of foundations typically used in offshore wind farm substations, i.e. monopile, tripod and gravity base, will be impractical. Jacket structures have been used for 'deepwater' sites such as in [11]; however this is only $45 \mathrm{~m}$ depth. The choices for an offshore substation in $100 \mathrm{~m}$ water depth would be;

- Strategically locating the wave farm in proximity to a $<50 \mathrm{~m}$ water depth location and locating the offshore substation at an midpoint between the wave farm and the shore 
- Building a jacket or compliant tower type structure such as those in use for oil platforms

- Building the substation on a floating platform such as the semi-submersible, tension leg or spar type structures in use for oil platforms

- Locating the offshore substation on the seabed

This key interface requires further study to establish the most cost effective option available.

\section{Conclusions}

This paper explored the technical issues surrounding a development path for electrical networks for future offshore wave farms. The paper concludes that key issues for offshore wind farm electrical networks are cost and efficiency. Following the same configurations as wind farms electrical networks are developed for small, medium and large wave farms which should provide a high level of efficiency. The characteristics of the Wave Energy converter and the site must be taken into account for establishing the 'true' energy yield efficiency.

It will be possible to establish small wave farms (<15MW) using $10 \mathrm{kV}$ infrastructure, however this will lead to large cable sizes within the array and particularly to shore. More suitable voltages are $20 \mathrm{kV}$ and $33 \mathrm{kV}$ within the array and for transmission up to 100MW with offshore substation and $132 \mathrm{kV}$ transmission required for transmission for large scale wave farms (>100MW)

Increasing the device spacing within the wave farm has a negligible effect on energy yield efficiency, particularly for larger arrays and does not require increasing cable CSA. There will, however, be a cost impact from having longer infield cables. Doubling the device spacing could add an additional $38 \%$ to the overall cable length of the infield and transmission system.

Redundancy can be introduced to the electrical networks, however at a financial cost. Redundancy may prove more important due to larger numbers of devices per radial in wave farms. Redundancy in the electrical network could form an integral part of the maintenance strategy also, however other solutions could be developed to overcome this.

There are a number of key interfaces which a WEC developer must consider at the early stages of device design. If these key interfaces are managed correctly the WEC can lend itself to a flexible, cost effective, and much standardised electrical network, which will make it attractive for deployment on an array scale.

The key differences between offshore wind and wave farms have been identified;

- WECs have lower MW ratings than wind turbines allowing more devices per radial

- Devices will require removal for maintenance having impact on circuit integrity

- Depth at the site is significantly deeper than any offshore wind farm and distance from shore could be further.

- Devices are not fixed structures making cable installation potentially complicated

\section{References}

[1] Offshore Renewable Energy Development Plan 2010 - http://www.dcenr.gov.ie/

[2] UK Renewable Energy Strategy 2009 - www.decc.gov.uk

[3] Equimar Deliverable 5.12009 - http://www.equimar.org/

[4] M. Kenny. Electrical Connection Issues for Wave Energy Arrays. Masters Thesis, University College Cork, 2010. 
[5] A. Kiprakis, A Nambiar, D. Forehand, A Wallace. Modelling Arrays of Wave Energy Converters Connected to Weak Rural Electrical Networks. International Conference on Sustainable Power Generation and Supply, 2009

[6] Czech, B.; Bauer, P.; Polinder, H.; Korondi, P. Modeling and simulating an Archimedes Wave Swing park in steady state conditions. 13th European Conference on Power Electronics and Applications, 2009.

[7] M. Molinas, O. Skjervheim, B. Sorby, P. Andreasen, S. Lundberg, T. Undeland. Power Smoothing by Aggregation of Wave Energy Converters for Minimizing Electrical Energy Storage Requirements. 7th European Wave and Tidal Energy Conference, 2007.

[8] T. Ahmed, A. Zobaa. Offshore power conditioning system connecting arrays of wave energy converters to the electric power grid. 8th International Conference on Advances in Power System Control, Operation and Management, 2009.

[9] M. Santos, D. Ben Haim, F. Salcedo, J. Villate, Y. Torre-Enciso. Grid Integration of Wave Energy Farms: Basque Country Study. 3rd International Conference on Ocean Energy, 2010

[10] D. O’Sullivan, G. Dalton. Challenges in the Grid Connection of Wave Energy Devices. 8th European Wave and Tidal Energy Conference, Uppsala, Sweden, 2009

[11] S. Breton, G. Moe. Status, Plans and Technologies for Offshore Wind Turbines in Europe and North America. Renewable Energy, 2009. Pg. 646-654

[12] J. Twidell and G. Gaudiosi - Offshore Wind Power. Multi Science Publishing, 2007

[13] H. Landsverk, O. Granhuag, P. Skryten, S. Rafoss. 36kV Vacuum Circuit Breaker Panel - The Perfect Switchgear for Wind. 20th International Conference on Electricity Distribution, Prague, Cezch Republic 2009

[14] J. Yang, J. O'Reilly, J. Fletcher. Redundancy Analysis of Offshore Wind Farm Collection and Transmission Systems. International Conference on Sustainable Power Generation and Supply 2009

[15] R. Green, N. Vasilakos. Economics of Offshore Wind. Energy Policy, 2010. Pg. 1-7

[16] W. Dick. 'Wave Energy Converter'. U.S. Patent Number 6857266

[17] J. Fitzgerald. Position Mooring of Wave Energy Converters. PhD Thesis, Chalmers University, Sweden. 2009 - pp 36

[18] C Fitzgerald, G. Thomas. A Preliminary Study on the Optimal Performance of an Array of Wave Power Devices. 7th European Wave and Tidal Energy Conference, 2007.

[19] P. Ricci, J-B Saulnier, A. Falcao. Point Absorber Arrays: A Configuration Study off the Portuguese West Coast. 7th European Wave and Tidal Energy Conference, 2007.

[20] ABB - Cables for Offshore Wind Farms. www.abb.com

[21] C. Moore. BICC Electrical Cables Handbook $3^{\text {rd }}$ Edition. Blackwell 1997.

[22] P. Karaliolios, A. Ishchenko, E. Coster, J. Myrzik, W. Kling. Overview of Short-Circuit Contribution of Various Distributed Generators on the Distribution Network.

[23] Renewable UK - Wind Turbine Safety Rules. http://www.bwea.com/safety/safety_rules.html

[24] UK National Grid - The Electricity Transmission Safety Rules $3^{\text {rd }}$ Edition. http://www.nationalgrid.com/ 